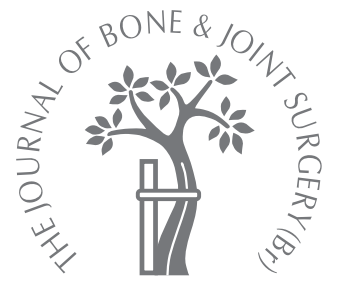

S. Patil, R. Montgomery

From James Cook University Hospital, Middlesbrough, England

S. Patil, MBBS, MRCSEd, Clinical Research Fellow R. Montgomery, FRCSEd, Consultant Orthopaedic Surgeon

Department of Orthopaedics James Cook University Hospital, Marton Road, Middlesbrough, TS4 3BW, UK.

Correspondence should be sent to Mr S. Patil; e-mail: sunitpatil@doctors.org.uk

(C2006 British Editorial Society of Bone and Joint Surgery doi:10.1302/0301-620X.88B7. $17639 \$ 2.00$

$J$ Bone Joint Surg $[\mathrm{Br}]$ 2006:88-B:928-32.

Received 10 January 2006; Accepted 30 March 2006

\title{
Management of complex tibial and femoral nonunion using the Ilizarov technique, and its cost implications
}

\author{
We reviewed 78 femoral and tibial nonunions treated between January 1992 and December \\ 2003. Of these, we classified 41 in 40 patients as complex cases because of infection (22), \\ bone loss (6) or failed previous surgery (13). The complex cases were all treated with \\ llizarov frames. At a mean time of $\mathbf{1 4 . 1}$ months (4 to 38), 39 had healed successfully. \\ Using the Association for the Study and Application of the Methods of llizarov scoring \\ system we obtained 17 excellent, 14 good, four fair and six poor bone results. The \\ functional results were excellent in 14 patients, good in 14, fair in two and poor in two. A \\ total of six patients were lost to follow-up and two had amputations so were not evaluated \\ for final functional assessment. All but two patients were very satisfied with the results. \\ The average cost of treatment to the treating hospital was approximately $£ 30000$ per \\ patient.
}

We suggest that early referral to a tertiary centre could reduce the morbidity and prolonged time off work for these patients. The results justify the expense, but the National Health Service needs to make financial provision for the reconstruction of this type of complex nonunion.

The senior author (RM) has been using the Ilizarov technique to treat nonunion of fractures for more than 15 years. It allows the use of compression, distraction, bone lengthening and correction of deformity, but because it is labour intensive its use is not widespread. Many tibial and femoral nonunions can be treated satisfactorily by internal fixation ${ }^{1,2}$ with or without bone grafting. However, infection, bone exposure, bone loss, deformity or failure of previous internal fixation are relative contraindications to internal fixation. In these more complicated cases, which we define as complex nonunions, the Ilizarov method is particularly valuable. The choice in such patients may be between limb salvage using the Ilizarov method and amputation.

It is important to evaluate the outcome and cost of this treatment in view of the considerable investment in time and resources by both the patient and the health service. To our knowledge, no previous studies evaluating the costs involved in treating complex nonunion have been published in the United Kingdom. The aim of this study was to assess the functional and radiological outcome in patients with complex femoral and tibial nonunion treated by the Ilizarov technique, as well as the costs involved.

\section{Patients and Methods}

We defined complex nonunion as an established nonunion (of at least six months in duration) with one or more of the following criteria: infection at the site of nonunion; a bone defect of more than $4 \mathrm{~cm}$ (defect nonunion); an attempt to achieve union that failed to heal after at least one supplementary intervention, for example, bone grafting or exchange nailing.

We retrospectively identified patients who had undergone Ilizarov treatment for femoral or tibial nonunion using theatre lists and appointment diaries. The notes and radiographs of these patients were reviewed and those who met the above criteria for complex nonunion were included in the study. The mechanism of initial injury, number of previous operations, and the method of internal or external fixation were noted. Infected nonunions were classified according to whether the infection was active or quiescent, and the amount of bone loss. ${ }^{3}$

Between January 1992 and December 2003, 78 patients were treated for femoral and tibial nonunion at our institution. Of these, 40 patients (41 nonunions) met the criteria for complex nonunion and were included in the study; of which 22 nonunions had an infection 
and the remaining 19 were not infected, but satisfied at least one other criterion (Table I).

There were 35 males and five females, with a mean age of 41 years (10 to 73 ). There were six proximal tibial nonunions, 25 tibial shaft nonunions, five distal tibial nonunions and five femoral shaft nonunions. Of the patients 30 $(75 \%)$ had been referred from other hospitals. Of the 41 nonunions, 21 had initially had an open fracture. Of these, six were grade 1 , four were grade 2 and 11 were grade 3 according to the Gustilo-Anderson system. ${ }^{4}$ The mechanism of the initial injury was a road traffic accident in 24 nonunions, a fall from a height in 12 , an industrial accident in three and a sports injury in two.

The mean number of operations undergone by each patient prior to referral was three (1 to 10 ). There were 15 fractures treated initially by plating, 14 by external fixation, six by plaster cast and six by intramedullary nailing. Of these, two patients developed nonunion in an Ilizarov frame which was applied as primary treatment for the fracture and two who had their fractures plated after intramedullary fixation were referred to us after the plates had failed.

Infected nonunions were referred at a mean of 15.9 months (6 to 96) after the original fracture, whereas noninfected nonunions were referred at a mean of 25.6 months (6 to 168). Despite being warned that smoking might delay bone healing, 19 of the 40 patients continued to smoke during treatment. Of the 40 patients, 14 had received nonsteroidal anti-inflammatory drugs (NSAIDs) at some stage during treatment of their original fracture. Three patients were addicted to alcohol and required detoxification on admission.

A bifocal compression distraction technique (compression of the nonunion with distraction at the corticotomy) was used in 20 nonunions. Monofocal treatment (simple stabilisation of the nonunion with compression and stimulation of union by distraction) was used in 21 nonunions. $^{5}$ Bone grafting was undertaken in 28 cases, bone morphogenic protein (BMP-7) was used in six, ultrasound in nine and electromagnetic induction in two cases. Some cases had more than one of these treatments.

At final follow-up an independent assessor (SP) not involved in the treatment assessed the patients for gait, limb-length discrepancy and range of movement of the adjacent joints. Functional and radiological outcomes were assessed using the Association for the Study and Application of Methods of Ilizarov (ASAMI) criteria described by Paley et al. ${ }^{6}$ In order to assess patient satisfaction, we used a visual analogue scale from 0 to 100 , with 0 being completely unsatisfied and 100 being completely satisfied. This method was used by Sanders et al. ${ }^{7}$ Our definition of union was the presence of bridging trabeculae on three cortices, absence of pain on dynamisation and absence of movement at the union site when screened using fluoroscopy. The cost of treatment was calculated for each patient using the estimate for the year 2004-2005 provided by the Finance Department of our hospital.
Table I. Types of infected nonunion

\begin{tabular}{lc}
\hline & Number of cases \\
\hline A1, Quiescent infection, defect $<4 \mathrm{~cm}$ & 1 \\
A2, Quiescent infection, defect $>4 \mathrm{~cm}$ & 5 \\
B1, actively discharging sinus, defect $<4 \mathrm{~cm}$ & 5 \\
B2, actively discharging sinus, defect $>4 \mathrm{~cm}$ & 11 \\
\hline
\end{tabular}

Table II. Complications of our treatment

\begin{tabular}{ll}
\hline & Number of cases \\
\hline Problems & 3 \\
$\quad$ Poor regenerate & All patients \\
$\quad$ Pin tract infection & 2 \\
Obstacles & 1 \\
$\quad$ Infection needing change of frame & 2 \\
Wire breakage & 1 \\
Re-fracture & \\
Fracture of regenerate & 2 \\
True complications & 1 \\
$\quad$ Chronic osteomyelitis & 2 \\
Deep venous thrombosis & \\
Persistent infection of pin tracts &
\end{tabular}

\section{Results}

The final functional outcome could not be assessed in eight patients. Of these, one had died of unrelated causes, one had developed dementia, four had moved and could not be contacted and two had an amputation. The mean follow-up time for the remaining 32 patients (33 cases) was 61.1 months (18 to 138) after removal of the frame. The bone results were calculated for all 40 patients ( 41 cases).

Of the 41 nonunions, 39 healed successfully, and the mean time to union was 14.1 months (4 to 38 ). There were two patients with persistent nonunion of the tibia who required below-knee amputation. The mean patient satisfaction score on a numerical scale ${ }^{7}$ from 0 to 100 was 92 . All but two patients said that they would undergo Ilizarov treatment if they were to suffer from a similar condition again. Of the 32 patients ( 33 nonunions) with successful treatment and a complete follow-up, seven did not work before or after treatment. A further 18 did not return to work after successful treatment, and only seven were able to return to work. No walking aid was required in 15 , a walking stick was used by 13 patients, two patients used one crutch and two patients required two crutches.

We classified the adverse effects of our treatment as problems, obstacles and true complications (Table II).

Two patients developed chronic osteomyelitis and one developed a septic ankle joint as the nonunion was in close proximity. He later required ankle fusion. One patient developed an infection adjacent to a broken tap, left behind during the first operation at the referring hospital.

Our results using the ASAMI criteria for outcome of nonunion are shown in Table III.

There were six poor bone results, two of which were refractures, two failed to unite and two united with other adverse factors. Both refractures were treated and subse- 
Table III. Results using Association for the Study and Application of the Methods of Ilizarov (ASAMI) scoring system ${ }^{6}$

\begin{tabular}{|c|c|c|}
\hline \multicolumn{3}{|l|}{ Bone results } \\
\hline Excellent & Union, no infection, deformity $<7^{\circ}$, limb-length discrepancy $<2.5 \mathrm{~cm}$ & 17 \\
\hline Good & $\begin{array}{l}\text { Union + any two of the following: } \\
\text { absence of infection, }<7^{\circ} \text { deformity and limb-length inequality of }<2.5 \mathrm{~cm}\end{array}$ & 14 \\
\hline Fair & $\begin{array}{l}\text { Union }+ \text { only one of the following: } \\
\text { absence of infection, deformity }<7^{\circ} \text { and limb-length inequality }<2.5 \mathrm{~cm}\end{array}$ & 4 \\
\hline Poor & $\begin{array}{l}\text { Nonunion/re-fracture/union + infection }+ \text { deformity }>7^{\circ}+\text { limb-length inequality } \\
>2.5 \mathrm{~cm}\end{array}$ & 6 \\
\hline \multicolumn{3}{|c|}{ Functional results } \\
\hline Excellent & $\begin{array}{l}\text { Active, no limp, minimum stiffness (loss of }<15^{\circ} \text { knee extension } /<15^{\circ} \text { dorsiflexion of } \\
\text { ankle), no reflex sympathetic dystrophy (RSD), insignificant pain }\end{array}$ & 14 \\
\hline Good & $\begin{array}{l}\text { Active, with one or two of the following: } \\
\text { limp, stiffness, RSD, significant pain }\end{array}$ & 14 \\
\hline Fair & $\begin{array}{l}\text { Active, with three or all of the following: } \\
\text { limp, stiffness, RSD, significant pain }\end{array}$ & 2 \\
\hline Poor & Inactive (unemployment or inability to return to daily activities because of injury) & $2(18)^{*}$ \\
\hline Failures & Amputation & 2 \\
\hline
\end{tabular}

* if all patients who lost employment as a result of the injury are added, the number of patients with a poor result would be 20. Note: six of the 40 patients were not available for functional assessment at final follow-up

Table IV. Details of the treatment
Mean time to union (mths)

Mean time as in-patient (days)

Mean number of follow-up appointments

Mean number of major operations following application of the frame

Mean number of minor operations following application of the frame
14.1 (4 to 38 )

48 (9 to 171 )

18 ( 2 to 52 )

3 (1 to 10$)$

2 (1 to 6$)$ quently achieved an excellent radiological and functional result. We did not consider patients who required bone grafting to be a poor result. ${ }^{5,8}$ There were two patients with a poor functional result, one of whom had a below-knee amputation on the opposite side and a fracture of the seventh thoracic vertebra without a neurological deficit. The main reason for his inactivity was back pain. The other had an established compartment syndrome from the initial fracture with a foot drop and an equinus contracture, which required correction using the Ilizarov frame.

The bone and functional outcomes were not always the same. In seven patients the functional outcome was better than the bone outcome, whereas in five patients the bone outcome was better than the functional outcome.

The mean number of days in hospital for each patient was 47 (9 to 171). Two patients were in hospital for more than 100 days. One of these was a child aged 10 years at the start of treatment, with defect nonunion, whose prolonged stay was due to social problems. The mean number of outpatient appointments was 18 (2 to 52) (Table IV).

The mean cost of hospital treatment and various operations after the application of the frame was $£ 23604$ per patient. If the cost of implants, radiological investigations, drugs and physiotherapy are also added, the cost per patient rose to approximately $£ 30000$. This excludes the cost of bone morphogenetic protein and ultrasound (Table V).

\section{Discussion}

Complex nonunions pose a formidable challenge to both surgeon and patient. The Ilizarov treatment has been successful in managing most problems in these patients, but it is not a panacea. There were two patients referred to us with complex nonunion who had developed it during primary treatment of their fracture with an Ilizarov frame.

Table V. Particulars of cost estimation (courtesy of the Finance Department, James Cook University Hospital)

\begin{tabular}{|c|c|c|}
\hline & Cost & Mean cost/patient \\
\hline \multicolumn{3}{|l|}{ Particulars } \\
\hline Costs for in-patient treatment & f248/night & $£ 12108$ \\
\hline Costs for first (orthopaedic) outpatient follow-up & $£ 150$ & $£ 150$ \\
\hline Costs for subsequent outpatient follow-up & f89.27/visit & $£ 1552$ \\
\hline Theatre running cost & $£ 18.43 / \mathrm{min}$ & £8605 \\
\hline Day-case theatre cost & f22.92/min & £1189 \\
\hline Total & & £23 604 \\
\hline \multicolumn{3}{|l|}{ Other costs (approximate) } \\
\hline In-patient radiographs and CT scans (25 films/patient) & £47/film & $£ 1175$ \\
\hline Physiotherapy (2 sessions/day) & £19.10/session & $£ 1795$ \\
\hline Cost of Ilizarov frame & $£ 2630$ & $£ 2630$ \\
\hline Total & & £29 204 \\
\hline
\end{tabular}


Table VI. A comparison of the results using Association for the Study and Application of the Methods of Ilizarov (ASAMI) criteria ${ }^{6}$

\begin{tabular}{|c|c|c|c|c|c|}
\hline Authors & Inclusion criteria & $\begin{array}{l}\text { Number of patients with } \\
\text { successful union and } \\
\text { follow-up }\end{array}$ & $\begin{array}{l}\text { Excellent, good, fair, } \\
\text { poor bone results (\%) }\end{array}$ & $\begin{array}{l}\text { Excellent, good, fair, } \\
\text { poor functional results } \\
(\%)\end{array}$ & $\begin{array}{l}\text { Returning } \\
\text { to work }(\%)\end{array}$ \\
\hline Dendrinos et $\mathrm{al}^{8}$ & Infected tibial nonunion & 27 & $50,28,4,18$ & $26,41,15,18$ & 82 \\
\hline Maini et al $^{5}$ & Infected nonunions & 30 & $70,10,0,20$ & $27,40,10,23$ & 77 \\
\hline Sanders et $\mathrm{al}^{7}$ & Tibial nonunions & 15 & $48,21,5,26$ & - & 62.5 \\
\hline McKee et $\mathrm{al}^{10}$ & $\begin{array}{l}\text { Failed previous surgery, infection, } \\
\text { complex deformities }\end{array}$ & 22 & $36,32,12,8$ & - & 86.7 \\
\hline Paley et al $^{6}$ & Defect nonunion $>1 \mathrm{~cm}$ & 25 & $72,20,8,0$ & $64,28,4,4$ & 60 \\
\hline Present study & Complex tibial and femoral nonunion & 32 & $42,34,10,14$ & $44,44,6,6(63)^{*}$ & 22 \\
\hline
\end{tabular}

* in our series, if we consider unemployment as a benchmark $63 \%$ would have a poor functional result

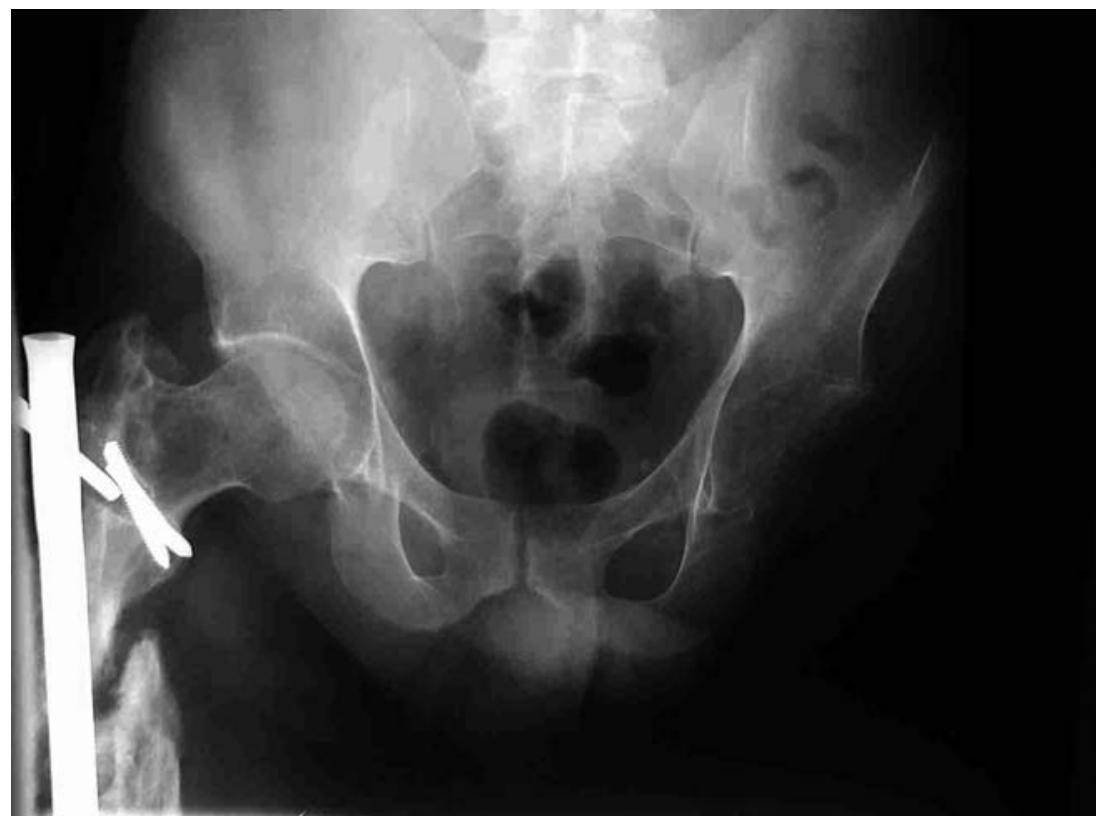

Fig. 1a

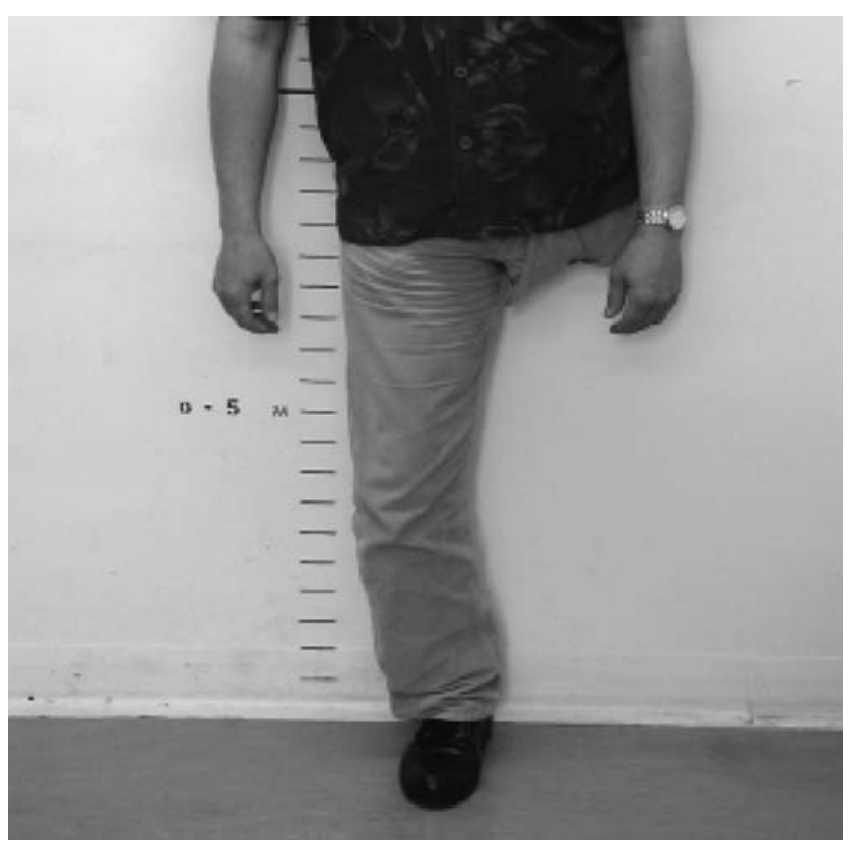

Fig. 1c

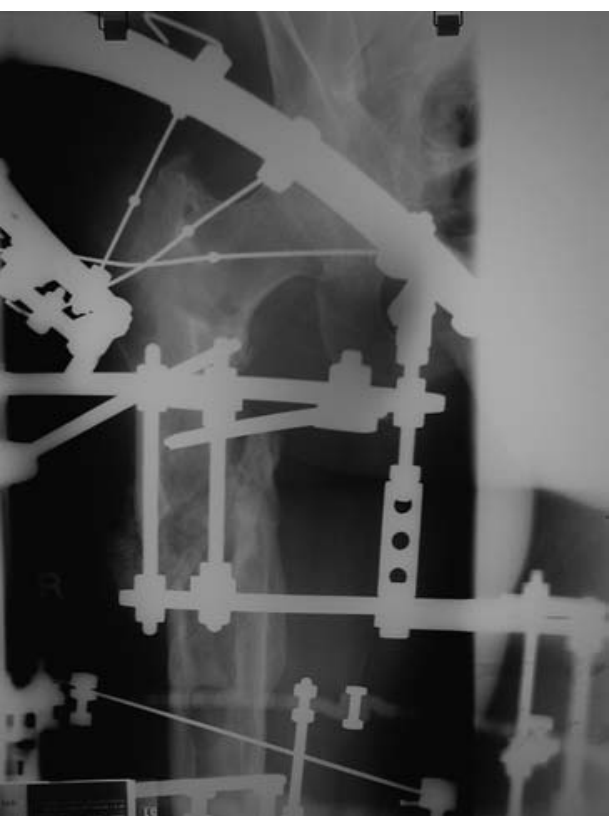

Fig. $1 b$ a) Radiograph showing an eight-year-old nonunion of the right proximal femur, with hip disarticulation on the opposite side; b) radiograph after the application of an Ilizarov frame; c) the patient after successful completion of treatment 
Judging fracture union is not always straightforward. Despite using stringent criteria we had two cases where we felt that the nonunion had healed when it had not. Of the nonunions referred to us, three had previously been discharged by the treating surgeon as 'united'. In all these cases the nonunions were close to joints, similar to the experience reported by Marsh et al. ${ }^{9}$ We have found CT scans helpful in the assessment of peri-articular nonunion when healing is in doubt.

The ASAMI outcome measurement divides the results into bone and functional. Several authors have used this system (Table VI)..$^{5-8,10}$

In all these papers, none of which are from the UK, the percentage of patients returning to work was fairly high. In comparison, 18 of our 32 patients available for functional assessment $(56 \%)$ did not return to work. We think this was influenced by the following factors:

Delay in referral. Infected nonunions were referred after a mean of 15.9 months (6 to 96), whereas non-infected nonunions were referred after a mean of 25.6 months (6 to 168). If the mean time for treatment is 14.1 months, and further rehabilitation time is at least three months, these patients are out of the labour market for more than 2.5 years for infected fractures and 3.25 years for uninfected fractures. Earlier referral could reduce this period. We recommend that all patients with complex nonunion of femoral and tibial fractures should be referred to a limb reconstruction centre by six months after injury.

Social benefits and compensation. All 18 patients who lost employment were on disability or incapacity benefits. Some received large compensation awards. Two of our patients commented that they 'did not bother to look for work'. Therefore using employment as a benchmark for assessing functional outcome may not necessarily reflect the true outcome, particularly in countries where people receive substantial unemployment and incapacity benefits.

Severity of injury or associated injury. At the start of this study, the senior author (RM) was the only surgeon using this method in a population of 2.6 million (north-east of England). Patients were generally referred when other methods could not be used or had already failed.

The overall outcome is affected by associated injuries. Often the result of the nonunion is satisfactory, but the patient's activities are restricted by the associated injuries. Those patients may need some assistance in their daily activities and would hence be classed as poor according to the ASAMI system.

As an example, a 47-year-old man with an eight-year-old infected nonunion of the right proximal femur was referred to us. He had a hip disarticulation on the other side from the original injury. The nonunion healed in an Ilizarov frame. He required some help in daily activities because of the contralateral hip disarticulation. The functional outcome was classed as a poor result using the original ASAMI system, as he lost his job, but the patient's satisfaction assessment was $100 \%$ (Fig. 1).
Patient satisfaction is of paramount importance. Marsh et $\mathrm{al}^{9}$ quoted a median patient satisfaction score of 6.5 of 7 (where 0 was not satisfied and 7 was completely satisfied). In this series, the mean patient satisfaction score was 92 on a scale of 0 to 100 , where 0 was not satisfied and 100 was completely satisfied.

In view of the above-mentioned shortcomings, we propose two modifications to the ASAMI system. First, using patient satisfaction instead of employment as a benchmark for functional outcome. A patient who is unable to carry out daily activities because of the nonunion and who has a patient satisfaction score of less than 50 on a visual analogue scale would be deemed to have a poor result. We do not think that employment is a direct marker of functional outcome, as it is influenced by so many social factors. Secondly, a re-fracture does not necessarily imply an inferior result if union is subsequently achieved. In our two cases an excellent functional result was achieved. Re-fracture is a problem but not ultimately a complication in the long term if union is achieved.

Most complex nonunions end up in large centres. At present, in the United Kingdom there is no system of reimbursement to adequately support limb reconstruction in these centres. We hope that our cost data will help clinicians and managers resolve this. The results in our view justify the costs of this treatment. Williams ${ }^{11}$ reported the average cost of treatment for limb reconstruction of tibial nonunions using the Ilizarov method to be $\$ 59213$ (approx. $£ 33752$ ), which is similar to our costs. Despite this, the results are satisfying both for the patient and for the surgeon.

\section{Supplementary Material}

$\because$ A table showing the details of the patients in this C study is available with the electronic version of this article on our website at www.jbjs.org.uk

The Research Fellow's post is funded by the Medical School (Teaching and Research Fellow).

No benefits in any form have been received or will be received from a commercial party related directly or indirectly to the subject of this article.

\section{References}

1. Kempf I, Grosse A, Rigaut P. The treatment of noninfected pseudarthrosis of the femur and tibia with locked intramedullary nailing. Clin Orthop 1986;212:142-54.

2. Muller ME, Thomas RJ. Treatment of non-union in fractures of long bones. Clin Orthop 1979;138:141-53.

3. Jain AK, Sinha S. Infected nonunions of long bones. Clin Orthop 2005;431:57-65.

4. Gustilo RB, Anderson JT. Prevention of infection in one thousand and twenty five open fractures of long bones. J Bone Joint Surg [Am] 1976;58-A:453-8.

5. Maini L, Chadha M, Vishwanath J, et al. The llizarov method in infected nonunion of fractures. Injury 2000;31:509-17.

6. Paley D, Catagni MA, Argnani F, et al. Ilizarov treatment of tibial nonunions with bone loss. Clin Orthop 1989;241:146-65.

7. Sanders DW, Galpin RD, Hosseini M, MacLeod MD. Morbidity resulting from the treatment of tibial nonunion with Ilizarov frame. Can J Surg 2002;45:196-200.

8. Dendrinos GK, Kontos S, Lyritsis E. Use of the llizarov technique for treatment of nonunion of the tibia associated with infection. J Bone Joint Surg [Am]1995;77-A:835-46.

9. Marsh DR, Shah S, Elliot J, Kurdy N. The llizarov method in nonunion, malunion and infection of fractures. J Bone Joint Surg [Br] 1997:79-B:273-9.

10. McKee M, Yoo D, Schemitsch EH. Health status after llizarov reconstruction of post traumatic lower-limb deformity. J Bone Joint Surg [Br] 1998;80-B:360-4.

11. Williams MO. Long-term cost comparison of major limb salvage using the llizarov method versus amputation. Clin Orthop 1994;301:156-8. 